\title{
Reflexões de dois jovens psiquiatras
}

\author{
Daniel L. C. Costa ${ }^{1}$ e Juliana Belo Diniz ${ }^{2}$
}

Ao final da residência médica em Psiquiatria, o psiquiatra recém-formado encontra-se apto a trabalhar em diferentes cenários de atuação. Ele pode dedicar-se aos cuidados de portadores de transtornos mentais num hospital psiquiátrico, hospital geral, hospital-dia, Centros de Atenção Psicossocial (CAPS), ambulatórios, unidades básicas de saúde (UBS), unidades de emergência e no seu consultório particular. Tendo em vista o elevado número de portadores de transtornos mentais comuns, como depressão e ansiedade, na população em geral, o psiquiatra que trabalha nas UBS, além de atuar diretamente na assistência a estes indivíduos, tem um papel fundamental no sentido de supervisionar o atendimento prestado pelas equipes dessas unidades, atividade denominada matriciamento. Em relação a procedimentos, além das consultas médicas, sessões de psicoterapia e supervisão de casos, a psiquiatria conta com a eletroconvulsoterapia e a estimulação magnética trasncraniana, ambas utilizadas para o tratamento de depressões refratárias e a primeira também para psicoses.

Outra possibilidade de atuação para o jovem psiquiatra é a carreira de pesquisador. De fato, nos últimos anos as pesquisas na área de neurociências vêm agregando importantes progressos no conhecimento acerca dos transtornos mentais. Estudos envolvendo neuroimagem, neurofisiologia, genética e biomarcadores revelam importantes pistas para o entendimento dos mecanismos envolvidos na fisiopatologia dos quadros psiquiátricos. Apesar de todo esse progresso, grande parte do conhecimento produzido nos laboratórios de pesquisa ainda tem aplicação limitada na prática clínica, ou seja, não faz parte da rotina do psiquiatra clínico, por exemplo, a solicitação de exames genéticos ou a dosagem de marcadores inflamatórios durante o atendimento aos seus pacientes.

Outrossim, a psicoterapia resta como uma prática viável e não menos importante ao jovem psiquiatra. E dizemos não menos importante, já que o paradigma atual de entendimento das doenças psiquiátricas como resultado de alterações predominantemente biológicas relega a um segundo plano tal prática, cujos mecanismos de ação, em nítida tentativa de alusão aos psicofármacos, carecem de explicações razoavelmente claras, atribuindo-se à psicoterapia um caráter menos científico, sendo, portanto menos recomendada. As dificuldades relacionadas à escolha por esse caminho não param por aí: ao atuar como psicoterapeuta, o médico precisa, em certa medida, fazer um luto com a Medicina, ensinamento transmitido pelo Dr. Oswaldo Ferreira Leite Netto, diretor do serviço de psicoterapia do IPq. Isso quer dizer que a proposta do tratamento psicoterápico não visa necessariamente à eliminação do sintoma e cura de determinada alteração, mas sim a um entendimento ampliado de tal disfunção.

Em resumo, a área de atuação do psiquiatra, apesar de ser baseada prioritariamente no atendimento clínico, é ampla e conta com diversas modalidades de inserção profissional. O diferencial da psiquiatria em relação a outras especialidades médicas está no

\footnotetext{
${ }^{1}$ Ex-preceptor da Graduação do Departamento de Psiquiatria da FMUSP. Psiquiatra colaborador do PROTOC (Projeto Transtornos do Espectro Obsessivo-Compulsivo) do Instituto de Psiquiatria do HC-FMUSP.

2Pós-doutoranda do Departamento de Psiquiatria da FMUSP. Psiquiatra colaboradora do PROTOC do Instituto de Psiquiatria do HC-FMUSP.
} 
uso de diferentes paradigmas para compreensão e tratamento da "doença"'. Apesar dos incontestáveis avanços das neurociências, não existem respostas para grande parte das situações clínicas vivenciadas pelo psiquiatra clínico. Dessa forma, tanto o campo de pesquisa continua aberto para exploração, assim como o uso de técnicas não classicamente "curativas", como a psicoterapia, continua fazendo parte do arsenal de intervenções psiquiátricas. Para aqueles que têm interesse em áreas relacionadas às ciências humanas, a psiquiatria talvez seja uma das opções de carreira médica que mais os aproxima do estudo das humanidades. Por outro lado, também é uma das opções que mais os aproxima do sofrimento humano para o qual não existe alívio. Como consequência, é preciso estar disponível para lidar com os sentimentos de impotência e frustração, além de estar disposto a escutar o paciente por longos períodos de tempo. 